\title{
A2B Adenosine Receptor Stimulation Down-regulates M-CSF-mediated Osteoclast Proliferation
}

\author{
Yoon Taek Oh and Na Kyung Lee ${ }^{\dagger}$ \\ Department of Medical Science, College of Medical Sciences, Soonchunhyang University, \\ Asan-Si, Chungnam 31538, Korea
}

\begin{abstract}
Bone-resorbing osteoclasts play a major role in maintaining bone homeostasis with bone-forming osteoblasts. Although it has been reported that A2B adenosine receptor (A2BAR) regulates osteoclast differentiation, its effects on apoptosis or proliferation of osteoclasts have been less-defined. Here, we demonstrate that A2BAR stimulation regulates macrophage-colony stimulating factor (M-CSF)-mediated osteoclast proliferation. Stimulation with a specific agonist of A2BAR, BAY 60-6583, significantly reduced M-CSF-mediated osteoclast proliferation in a time- and dose-dependent manner. In addition, A2BAR stimulation induced both apoptosis of the cells and cell arrest in the G1 phase with a decrease of cell number in the G2/M phase. Stimulation with BAY 60-6583 inhibited the activation of Akt by M-CSF, whereas M-CSF-induced ERK1/2 activation was not affected. These results suggest that the inhibition of M-CSF-mediated Akt activation by A2BAR stimulation increases apoptotic response of osteoclasts and induces cell cycle arrest in the G1 phase, thus contributing to the down-regulation of osteoclast proliferation.
\end{abstract}

Key Words: M-CSF, Osteoclast proliferation, A2B adenosine receptor, Akt

\section{INTRODUCTION}

Bone is a dynamic tissue that undergoes constant remodeling by bone-forming osteoblasts and bone-resorbing osteoclasts. The functional balance between these two cell types is critical for bone homeostasis (Harada and Rodan, 2003; Teitelbaum, 2000). Osteoclasts are multinucleated cells derived from hematopoietic progenitors of the bone marrowderived monocyte/macrophage (BMM) lineage. Osteoclast differentiation and function are regulated by two major cytokines, macrophage-colony stimulating factor (M-CSF) and receptor activator of NF- $\mathrm{kB}$ ligand (RANKL) (Teitelbaum,
2000; Teitelbaum and Ross, 2003; Ross, 2006).

In animal models, op/op mice that fail to express functional M-CSF and mice lacking the gene ( $C s f l r)$ encoding M-CSF receptor exhibit severe osteopetrosis due to a decrease in tissue macrophages and a lack of osteoclasts (Kodama et al., 1991; Wiktor-Jedrzejczak et al., 1990; Dai et al., 2002), and these observations point to the important role of M-CSF in osteoclast biology. Binding of M-CSF to c-Fms, an MCSF receptor, autophosphorylates seven tyrosine residues in the cytoplasmic domain of the receptor (Ross, 2006; Faccio et al., 2007; Pixley et al., 2004); this stimulates a signaling cascades that lead to the proliferation, survival and differentiation of osteoclasts (Pixley et al., 2004; Bradley et al., 2008).

* Received: September 2, 2017 / Accepted: September 18, 2017

${ }^{\dagger}$ Corresponding author: Na Kyung Lee. Department of Medical Science, College of Medical Science, Soonchunhyang University, Asan-Si, Chungnam 31538 , Korea.

Tel: +82-41-530-3036, Fax: +82-41-530-3085, e-mail: nlee@sch.ac.kr

(C) The Korean Society for Biomedical Laboratory Sciences. All rights reserved.

(C) This is an Open Access article distributed under the terms of the Creative Commons Attribution Non-Commercial License (http://creativecommons.org/licenses/by-nc/3.0/) which permits unrestricted non-commercial use, distribution, and reproduction in any medium, provided the original work is properly cited. 
The activation of ERK1/2 MAP kinase and phosphatidylinositol (PI)3/Akt by M-CSF leads to osteoclast proliferation and survival (Ross, 2006; Pixley et al., 2004; Bradley et al., 2008). Especially, Akt pathway transduces anti-apoptotic signals by preventing the activation of the apoptotic signaling pathways and facilitates cell cycle progression (Xing and Boyce, 2005; Tanaka et al., 2006; Gingery et al., 2003).

When bones are damaged, increased extracellular ATP produces adenosine, a purine nucleoside produced in response to low-oxygen and inflammatory stimuli (Mediero and Cronstein, 2013; Bowler et al., 2001; Orriss et al., 2010). Adenosine binds to four adenosine receptors (A1R, A2AR, $A 2 B A R$ and $A 3 R$ ) that are members of the $G$ proteincoupled receptor family for the specific actions (Mediero and Cronstein, 2013; Bowler et al., 2001; Orriss et al., 2010). Although all four adenosine receptors are expressed in osteoclasts, they have different effects. Stimulation of A2AR, A2BAR and A3R inhibits osteoclast differentiation and function, whereas A1R stimulates it (Mediero and Cronstein, 2013; Orriss et al., 2010; Ham and Evans, 2012; Kara et al., 2010). A2BAR stimulation by its specific agonist BAY 60-6583 promotes osteoblast differentiation through modulation of Runx 2 and Osterix levels and decreases osteoclast differentiation (Corciulo et al., 2016; Carroll et al., 2012; Trincavelli et al., 2014). Moreover, it has been reported that A2BAR represents a $\mathrm{p} 53$-induced cell death priming receptor that stimulates apoptosis by sensing the accumulation of extracellular adenosine (Long et al., 2013). However, the effects of A2BAR on apoptosis or proliferation of osteoclasts have been little studied.

Here, we show for the first time that A2BAR stimulation inhibits M-CSF-mediated osteoclast proliferation by inducing apoptosis and arresting cells in G1 phase by blocking Akt signaling. These findings could help elucidate the pathophysiology of bone-related diseases and lead to the development of new treatment strategies.

\section{MATERIALS AND METHODS}

\section{Cell culture and Isolation of osteoclast precursors}

RAW264.7 preosteoclasts (Korean Cell Line Bank) were maintained in DMEM (Hyclone) containing 10\% FBS with antibiotics. Isolation of bone marrow precursors was performed as described previously (Oh et al., 2015). Briefly, bone marrow cells were flushed out from the femurs of 4-6-week-old C57BL/6 mice with a sterile 21-gauge needle and incubated in alpha-MEM media containing 10\% FBS and $10 \mathrm{ng} / \mathrm{mL}$ M-CSF (R\&D Systems). After 24 hours, nonadherent cells were harvested and cultured in the presence of M-CSF (20 ng/mL) for 3 days. After washing out the non-adherent cells, adherent cells were used as osteoclast precursors.

\section{BrdU incorporation assay}

The cell proliferation assay was performed as described previously (Lee and Lee, 2014) using a BrdU Cell Proliferation Assay Kit (Cell Signaling Technology). Briefly, after 24 hours of seeding 96-well plates with $2 \times 10^{4}$ cells/well, the cells were treated with or without BAY 60-6583 (Tocris Biosience). BrdU was added 12 hours before culture termination. At the end of the culture period, the cells were fixed with fixing solution for 30 minutes at room temperature, rinsed twice with phosphate-buffered saline, incubated with monoclonal anti-BrdU antibody for 1 hour followed by antimouse secondary antibody for 30 minutes. After the final wash, substrate was added to the wells followed by stop solution. The proportion of total cells incorporating BrdU into the nucleus was determined by reading the absorbance on a microplate reader (Bio-Rad) at a wavelength of $450 \mathrm{~nm}$ according to the manufacturer's instructions.

\section{Real-time PCR}

Total RNA was isolated from the cells treated with M-CSF (20 ng/mL) and/or BAY 60-6583 (5 $\mu \mathrm{M})$ and reverse transcribed using SuperScript ${ }^{\circledR}$ III reverse transcriptase (RT) (Invitrogen) according to the manufacturer's protocol. Realtime PCR was performed with the Brilliant UltraFast SYBR ${ }^{\circledR}$ Green QPCR Master Mix (Agilent Technologies) in triplicate using an Mx3000P instrument (Agilent Technologies). Specific primers for the indicated genes and hprt (for endogenous control) were purchased from QIAGEN. The thermal cycling conditions were as follows: $3 \mathrm{~min}$ at $95^{\circ} \mathrm{C}$, then 40 cycles of $95^{\circ} \mathrm{C}$ for 10 seconds and $60^{\circ} \mathrm{C}$ for 20 seconds, followed by 1 cycle of $95^{\circ} \mathrm{C}$ for 1 minute, $55^{\circ} \mathrm{C}$ for 30 
seconds, and $95^{\circ} \mathrm{C}$ for 30 seconds. All quantitation was normalized to hprt (Oh et al., 2015).

\section{Western blot analysis}

Osteoclast precursors were stimulated with M-CSF (20 $\mathrm{ng} / \mathrm{mL})$ and/or BAY 60-6583 $(5 \mu \mathrm{M})$ for the indicated times then lysed in lysis buffer (20 mM Tris-HCl, pH 7.5, $150 \mathrm{mM}$ $\mathrm{NaCl}, 1 \mathrm{mM} \mathrm{Na}{ }_{2}$ EDTA, $1 \mathrm{mM}$ EGTA, 1\% Triton, $2.5 \mathrm{mM}$ sodium pyrophosphate, $1 \mathrm{mM}$ beta-glycerophosphate, $1 \mathrm{mM}$ $\mathrm{Na}_{3} \mathrm{VO}_{4}, 1 \mu \mathrm{g} / \mathrm{mL}$ leupeptin, and $1 \mathrm{mM}$ phenylmethylsulfonylfluoride), and whole cell extracts were prepared by centrifugation. The supernatants were electrophoresed on a $10 \%$ SDS-polyacrylamide gel and blotted onto a polyvinylidene difluoride membrane. Immunoblot detection was performed with polyclonal antibodies specific to phosphoERK1/2, ERK1/2, phospho-Akt, Akt (Cell Signaling Technology, Beverly, MA), and $\beta$-actin (as a loading control, Santa Cruz Biotechnology Inc), followed by HRP-conjugated secondary antibodies and enhanced using an ECL detection kit (Amersham Biosciences) (Oh et al., 2015).

\section{Apoptosis assay}

Apoptosis was measured using the Annexin V Apoptosis Detection Kit (Millipore) according to the manufacturer's instruction. Twelve-well plates were seeded with $5 \times 10^{5}$ osteoclast precursor cells/well then treated with BAY 606583 as indicated in the presence of M-CSF $(20 \mathrm{ng} / \mathrm{mL})$ for 48 hours. The cells were then washed with cold phosphatebuffered saline, resuspended in $1 \times$ Annexin $\mathrm{V}$ binding buffer, and labeled with $100 \mu \mathrm{L}$ Annexin V-APC for 20 minutes in the dark. After the $1 \times$ binding buffer was added, the analysis was performed using a Muse ${ }^{\circledR}$ Cell Analyzer (Millipore).

\section{Cell cycle assay}

After 24 hours of seeding 12 -well plates with $5 \times 10^{5}$ cells /well, the cells were treated with BAY $60-6583$ as indicated in the presence of M-CSF $(20 \mathrm{ng} / \mathrm{mL})$ for 48 hours. The cells were then fixed with $70 \% \mathrm{EtOH}$ at $-20^{\circ} \mathrm{C}$ for 4 hours. After removing the $\mathrm{EtOH}$, the cells were reacted with the Muse $^{\circledR}$ Cell Cycle Assay Kit (Millipore) according to the manufacturer's instructions and then analyzed with a Muse ${ }^{\circledR}$
Cell Analyzer (Millipore).

\section{Statistical analysis}

Results are presented as means \pm standard deviations (SD) from at least 3 independent experiments and statistical analyses were determined using Student's $t$ test, if not, indicated. $P<0.05$ was considered to be statistically significant.

\section{RESULTS}

\section{A2BAR stimulation decreased M-CSF-mediated osteo- clast proliferation}

To determine whether A2BAR stimulation regulates osteoclast proliferation, BAY 60-6583, a specific agonist of A2BAR, was added to RAW264.7 cells or primary osteoclast precursors isolated from the bone marrow of mice femurs. The BrdU incorporation assay showed that BAY 60-6583 significantly reduced proliferation of both cell types in a dose-dependent manner. The most obvious effect was observed 48 hours after treatment with $5 \mu \mathrm{M}$ BAY 60-6583 in both cell types, which decreased the proliferation of RAW264.7 cells and osteoclast precursor cells by more than $25 \%$ and $15 \%$, respectively (Fig. 1A and $1 \mathrm{~B}$ ). In particular, stimulation with BAY 60-6583 inhibited M-CSF-induced proliferation of primary osteoclast precursors in a timedependent manner (Fig. 1C). These results indicate that A2BAR stimulation down-regulates osteoclast proliferation.

\section{A2BAR stimulation induced apoptosis and caused an arrest of cells at the G1 phase}

To determine whether the decrease in osteoclast proliferation was due in part to an increase in apoptosis and/or a change of cell cycle, we first investigated the effect of A2BAR stimulation on the apoptosis of osteoclasts. Stimulation with BAY 60-6583 in the presence of M-CSF increased the apoptosis of osteoclast precursors in a dosedependent manner (Fig. 2). The following experiment was conducted to determine whether A2BAR stimulation regulates the cell cycle of osteoclast precursors. BAY 60-6583treated cells increased the accumulation of cells at the G1 phase with a decrease in G2/M phase (Fig. 3). Taken together, these results suggest that the increase of apoptosis and the 
A

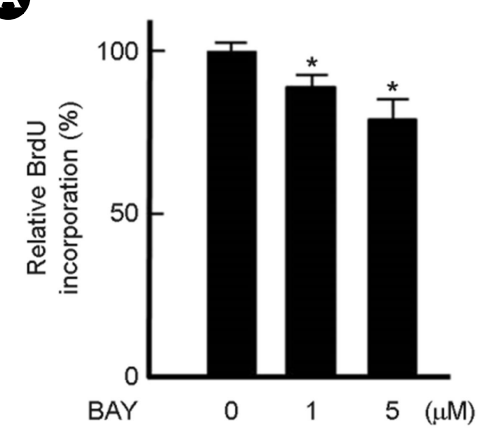

B

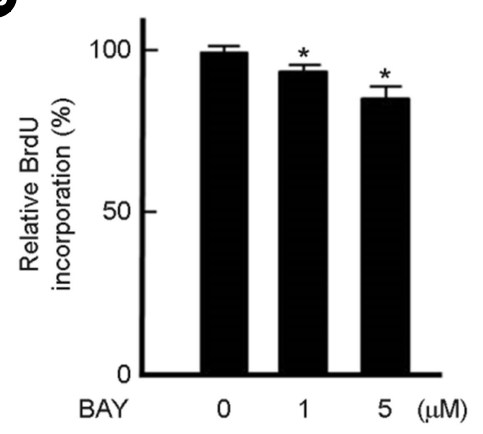

C

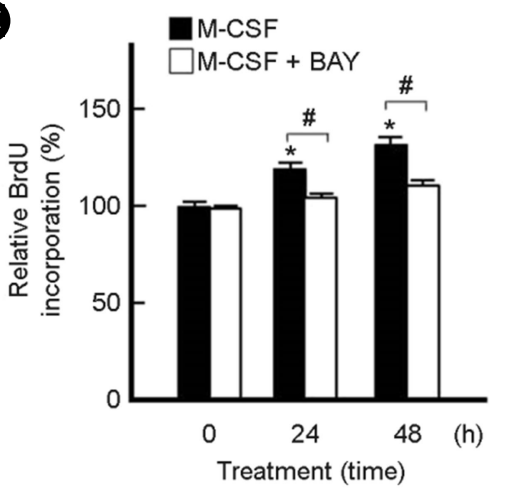

Fig. 1. Effect of A2BAR stimulation on cell proliferation. (A-C) RAW264.7 cells (A) or primary osteoclast precursors (B) were treated with the indicated concentrations of BAY $60-6583$ for $48 \mathrm{~h}$ or primary osteoclast precursors were treated with $5 \mu \mathrm{M}$ BAY $60-6583$ in the presence of M-CSF $(20 \mathrm{ng} / \mathrm{mL})$ for the indicated times $(C)$. Cell proliferation was measured using the BrdU Cell Proliferation Assay Kit. $* P<0.05$ vs. non-treated cells (A-C). $\# P<0.05$ vs. M-CSF-treated cells (C).
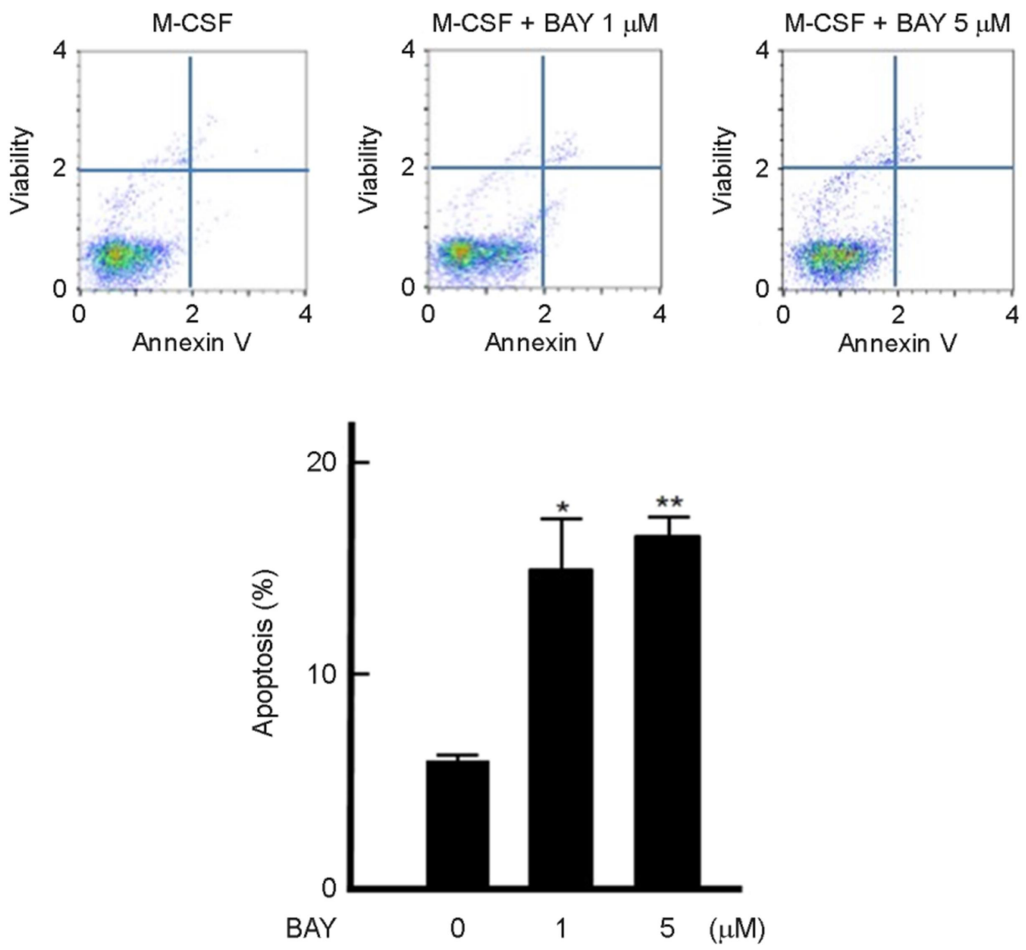

Fig. 2. The regulation of apoptosis by BAY 60-6583 treatment. Osteoclast precursors were treated with the indicated concentrations of BAY 60-6583 (BAY) for $48 \mathrm{~h}$ in the presence of $\mathrm{M}$ CSF $(20 \mathrm{ng} / \mathrm{mL})$. Apoptosis was measured using an Annexin V apoptosis kit and the Muse ${ }^{\mathbb{B}}$ Cell Analyzer as described in Materials and Methods. Results are representative of at least three independent experiments. $* P<0.05$ and $* * P<$ 0.005 vs. non-treated cells.

arrest of cells at the G1 phase may be responsible for the decrease in osteoclast proliferation by A2BAR stimulation.

\section{A2BAR stimulation inhibited the activation of Akt by M-CSF}

Since the activation of ERK1/2 and Akt is important for M-CSF-mediated osteoclast survival and proliferation (Kodama et al., 1991), we examined whether A2BAR stimulation modulated the activation of ERK1/2 and Akt by M-CSF. The activation of ERK1/2 and Akt peaked after 5 minutes of M-CSF treatment followed by a progressive decline in the activity of these kinases to basal levels. The 

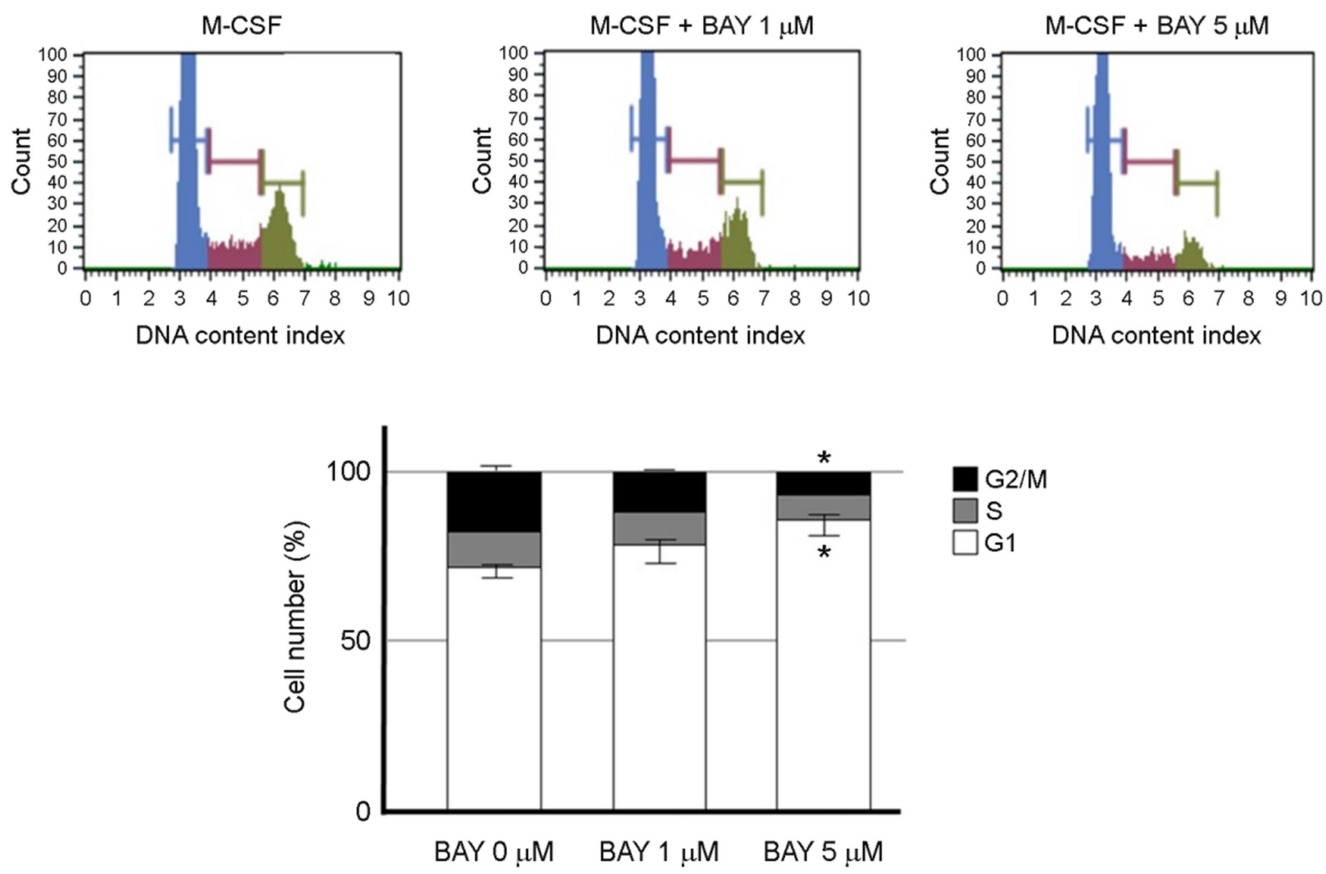

Fig. 3. Cell cycle regulation by BAY 60-6583 treatment. Osteoclast precursors were treated with the indicated concentrations of BAY 60-6583 (BAY) for $48 \mathrm{~h}$ in the presence of M-CSF $(20 \mathrm{ng} / \mathrm{mL})$. The cell cycle was analyzed using the Muse ${ }^{\mathbb{B}}$ Cell Cycle Kit and Muse ${ }^{\mathbb{B}}$ Cell Analyzer as described in Materials and Methods. Results are representative of at least three independent experiments. $* P<0.05$ vs. non-treated cells.
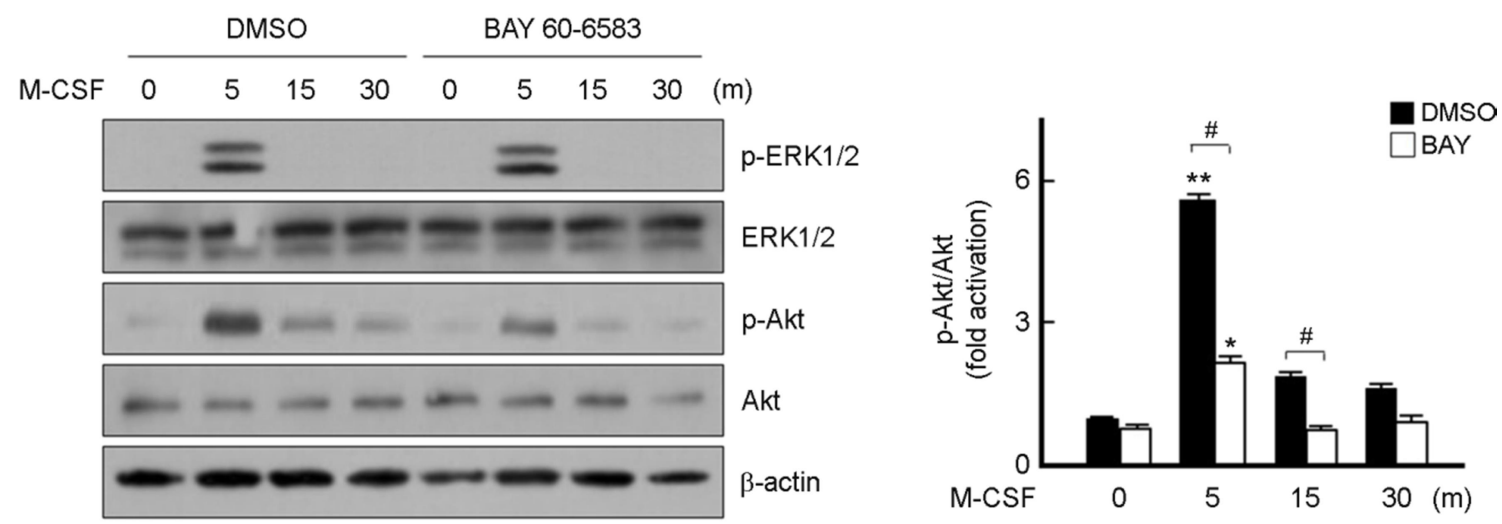

Fig. 4. A2BAR stimulation inhibits the activation of Akt by M-CSF. BMMs were treated with DMSO or BAY 60-6583 $(5 \mu \mathrm{M})$ in the presence of M-CSF $(20 \mathrm{ng} / \mathrm{mL})$ for the indicated times. Total proteins were isolated and subjected to Western blot analyses using MAP kinases-specific antibodies. $\beta$-actin is shown as a loading control (left). Protein bands were quantified by densitometry, and the level of phosphorylated Akt was normalized to that of Akt (right). ${ }^{*} P<0.05$ and ${ }^{* *} P<0.005$ vs. non-treated cells. $\# P<0.05$ vs. M-CSF-treated cells.

addition of BAY 60-6583 specifically inhibited the activation of Akt by M-CSF, whereas M-CSF-induced ERK1/2 activation was not affected by BAY 60-6583 treatment (Fig. 4). These results imply that the inhibition of M-CSF-mediated
Akt activation by A2BAR stimulation results in the decrease of osteoclast proliferation. 


\section{DISCUSSION}

Bone remodeling requires a constant supply of energy; adenosine, the metabolite generated by the breakdown of extracellular nucleotide molecules such as ATP, accumulates under conditions of cellular stress or altered metabolism such as bone fracture and bone repair (Mediero and Cronstein, 2013; Bowler et al., 2001; Orriss et al., 2010; Ham and Evans, 2012). In a previous study, we investigated the differential expression of genes by RANKL treatment during osteoclast differentiation by screening the cDNA microarray data; we found that Adora $2 b$ was induced after 24 hours of RANKL treatment (Kim and Lee, 2014). A2BAR is known to regulate bone homeostasis; Adora2b knockout mice showed a de- crease in bone mineral density due to impaired osteoblast differentiation and increased osteoclast differentiation (Corciulo et al., 2016; Carroll et al., 2012). However, the role of A2BAR on osteoclast proliferation and its underlying mechanism remain unclear. Here, we demonstrated the effect and underlying mechanism of A2BAR stimulation on M-CSF-mediated osteoclast proliferation.

A2BAR stimulation down-regulated osteoclast proliferation through two distinct mechanisms. First, A2BAR stimulation induced the arrest of cells at the G1 phase. Second, A2BAR stimulation stimulated apoptosis. ERK1/2 MAP kinase and PI3K/Akt are key mediators of M-CSF signaling for osteoclast proliferation (Ross, 2006; Bradley et al., 2008; Gingery et al., 2003). The Akt pathway in particular prevents the activation of apoptotic signaling pathways and promotes cell cycle progression (Xing and Boyce, 2005; Tanaka et al., 2006; Gingery et al., 2003). Interestingly, A2BAR stimulation specifically inhibited Akt activation by M-CSF, but ERK1/ 2 activation was not affected. These results increase the possibility that the inhibition of Akt by A2BAR stimulation is responsible for the increased apoptosis and the induction of cell cycle arrest at the G1 phase. Further studies using knock-down systems, such as Akt shRNA, are needed to examine the direct involvement of Akt on the regulation of osteoclast proliferation by A2BAR stimulation.

Although we have shown the regulatory mechanisms of A2BAR stimulation on osteoclast precursor proliferation, we cannot exclude the possibility that the other adenosine receptors may be involved, given the crucial roles of adenosine receptors on osteoclast biology. Moreover, since altered bone metabolism leads to changes in the extracellular adenosine concentration and adenosine receptors have different affinities for adenosine (Strazzulla and Bruce, 2016), it would be intriguing to test whether the effects of adenosine receptors on osteoclast proliferation are dependent upon the adenosine concentration.

Taken together, our results suggest that the induction of cell cycle arrest at the G1 phase and the increased apoptotic response through the inhibition of M-CSF-induced Akt activation by A2BAR stimulation contribute to the downregulation of osteoclast proliferation. These results provide a basis for understanding the pathophysiology of bone-related diseases and identify A2BAR as a potential therapeutic target.

\section{ACKNOWLEDGMENTS}

This work was supported by the Soonchunhyang University.

\section{CONFLICT OF INTEREST}

No conflicts of interest, financial or otherwise, are declared by the authors.

\section{REFERENCES}

Bowler WB, Buckley KA, Gartland A, Hipskind RA, Bilbe G, Gallagher JA. Extracellular nucleotide signaling: A mechanism for integrating local and systemic responses in the activation of bone remodeling. Bone. 2001. 28: 507-512.

Bradley EW, Ruan MM, Vrable A, Oursler MJ. Pathway crosstalk between Ras/Raf and PI3K in promotion of M-CSF-induced MEK/ERK-mediated osteoclast survival. Journal of Cellular Biochemistry. 2008. 104: 1439-1451.

Carroll SH, Wigner NA, Kulkarni N, Johnston-Cox H, Gerstenfeld LC, Ravid K. A2b adenosine receptor promotes mesenchymal stem cell differentiation to osteoblasts and bone formation in vivo. Journal of Cellular Biochemistry. 2012. 287: 15718 -15727 .

Corciulo C, Wilder T, Cronstein BN. Adenosine a $2 \mathrm{~b}$ receptors play an important role in bone homeostasis. Purinergic Signalling. 2016. 12: 537-547. 
Dai XM, Ryan GR, Hapel AJ, Dominguez MG, Russell RG, Kapp S, Sylvestre V, Stanley ER. Targeted disruption of the mouse colony-stimulating factor 1 receptor gene results in osteopetrosis, mononuclear phagocyte deficiency, increased primitive progenitor cell frequencies, and reproductive defects. Blood. 2002. 99: 111-120.

Faccio R, Takeshita S, Colaianni G, Chappel J, Zallone A, Teitelbaum SL, Ross FP. M-CSF regulates the cytoskeleton via recruitment of a multimeric signaling complex to c-fms tyr-559/697/721. Journal of Cellular Biochemistry. 2007. 282: 18991-18999.

Gingery A, Bradley E, Shaw A, Oursler MJ. Phosphatidylinositol 3-kinase coordinately activates the mek/erk and akt/nfkappab pathways to maintain osteoclast survival. Journal of Cellular Biochemistry. 2003. 89: 165-179.

Ham J, Evans BA. An emerging role for adenosine and its receptors in bone homeostasis. Frontiers in Endocrinology. 2012. 3: 113.

Harada S, Rodan GA. Control of osteoblast function and regulation of bone mass. Nature. 2003. 423: 349-355.

Kara FM, Chitu V, Sloane J, Axelrod M, Fredholm BB, Stanley ER, Cronstein BN. Adenosine al receptors (a1rs) play a critical role in osteoclast formation and function. FASEB J. 2010. 24: 2325-2333.

Kim HS, Lee NK. Gene expression profiling in osteoclast precursors by insulin using microarray analysis. Molecules and Cells. 2014. 37: 827-832.

Kodama H, Nose M, Niida S, Yamasaki A. Essential role of macrophage colony-stimulating factor in the osteoclast differentiation supported by stromal cells. Journal of Experimental Medicine. 1991. 173: 1291-1294.

Lee JY, Lee NK. Up-regulation of CyclinD1 and Bcl2A1 by insulin is involved in osteoclast proliferation. Life Sciences. 2014. 114: 57-61.

Long JS, Crighton D, O'Prey J, Mackay G, Zheng L, Palmer TM, Gottlieb E, Ryan KM. Extracellular adenosine sensing-a metabolic cell death priming mechanism downstream of p53. Molecules and Cells. 2013. 50: 394-406.

Mediero A, Cronstein BN. Adenosine and bone metabolism. Trends in Endocrinology and Metabolism. 2013. 24: 290-300.

Oh JH, Lee JY, Joung SH, Oh YT, Kim HS, Lee NK. Insulin enhances rankl-induced osteoclastogenesis via ERK1/2 activation and induction of NFATc1 and Atp6v0d2. Cellular Signalling. 2015. 27: 2325-2331.
Orriss IR, Burnstock G, Arnett TR. Purinergic signalling and bone remodelling. Current Opinion in Pharmacology. 2010. 10: 322 -330 .

Pixley FJ, Stanley ER. Csf-1 regulation of the wandering macrophage: Complexity in action. Trends In Cell Biology. 2004. 14: 628-638

Ross FP. M-CSF, c-Fms, and signaling in osteoclasts and their precursors. Annals of the New York Academy of Sciences. 2006. 1068: 110-116.

Strazzulla LC, Cronstein BN. Regulation of bone and cartilage by adenosine signaling. Purinergic Signalling. 2016. 12: 583-593.

Tanaka S, Miyazaki T, Fukuda A, Akiyama T, Kadono Y, Wakeyama H, Kono S, Hoshikawa S, Nakamura M, Ohshima Y, Hikita A, Nakamura I, Nakamura K. Molecular mechanism of the life and death of the osteoclast. Annals of the New York Academy of Sciences. 2006. 1068: 180-186

Teitelbaum SL. Bone resorption by osteoclasts. Science. 2000. 289: 1504-1508.

Teitelbaum SL, Ross FP. Genetic regulation of osteoclast development and function. Nature Reviews Genetics. 2003. 4: 638 -649 .

Trincavelli ML, Daniele S, Giacomelli C, Taliani S, Da Settimo F, Cosimelli B, Greco G, Novellino E, Martini C. Osteoblast differentiation and survival: A role for $\mathrm{a} 2 \mathrm{~b}$ adenosine receptor allosteric modulators. Biochimica et Biophysica Acta (BBA) - Molecular Cell Research. 2014. 1843: 2957-2966.

Wiktor-Jedrzejczak W, Bartocci A, Ferrante AW, Jr., Ahmed-Ansari A, Sell KW, Pollard JW, Stanley ER. Total absence of colonystimulating factor 1 in the macrophage-deficient osteopetrotic (op/op) mouse. Proceedings of the National Academy of Sciences of the United States of America. 1990. 87: 4828 -4832 .

Xing L, Boyce BF. Regulation of apoptosis in osteoclasts and osteoblastic cells. Biochemical and Biophysical Research Communications. 2005. 328: 709-720.

https://doi.org/10.15616/BSL.2017.23.3.194

Cite this article as: Oh YT, Lee NK. A2B Adenosine Receptor Stimulation Down-regulates M-CSF-mediated Osteoclast Proliferation. Biomedical Science Letters. 2017. 23: 194-200. 